\title{
Polycystic ovaries in leprechaunism
}

\author{
Denise Drohobyczer • Richard Bellah
}

Received: 22 May 2009/Revised: 9 July 2009/Accepted: 10 July 2009/Published online: 18 August 2009

(C) Springer-Verlag 2009

A 2-month-old girl presented with increasing abdominal girth and failure to thrive. Pelvic US showed an enlarged right ovary containing multiple cysts (Fig. 1). The left ovary appeared the same. A slightly enlarged uterus with pubertal configuration and prominent endometrium is also shown (Fig. 2, arrows).

Dr. William Donohue of the Hospital for Sick Children in Toronto first reported leprechaunism (also known as Donohue syndrome) in 1954. Physical features included growth retardation, lipoatrophy, acanthosis nigricans, hypertrichosis, abnormal facies, breast tissue hyperplasia, and enlarged genitalia. Endocrine dysfunction was suggested by abnormal glucose levels and profound insulin resistance. Autopsies revealed pancreatic islet cell hyperplasia and cystic ovaries [1].

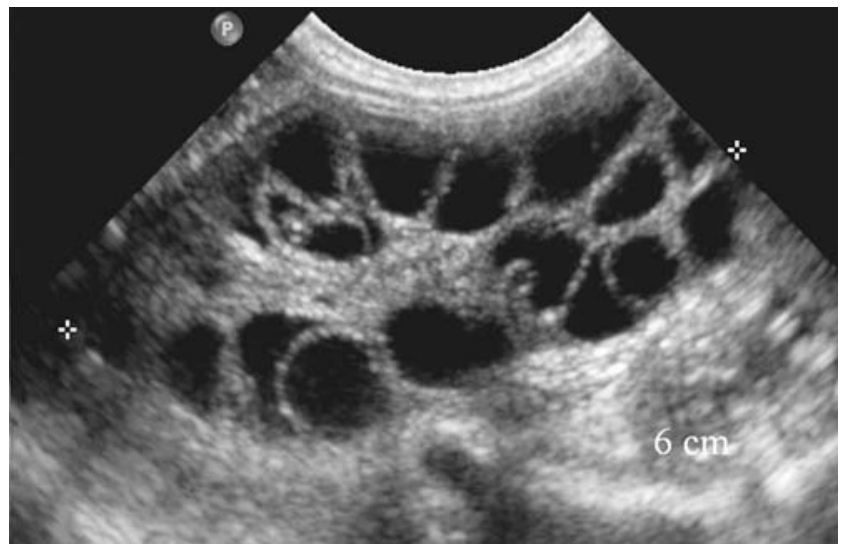

Fig. 1 Pelvic US shows enlarged right ovary with multiple cysts

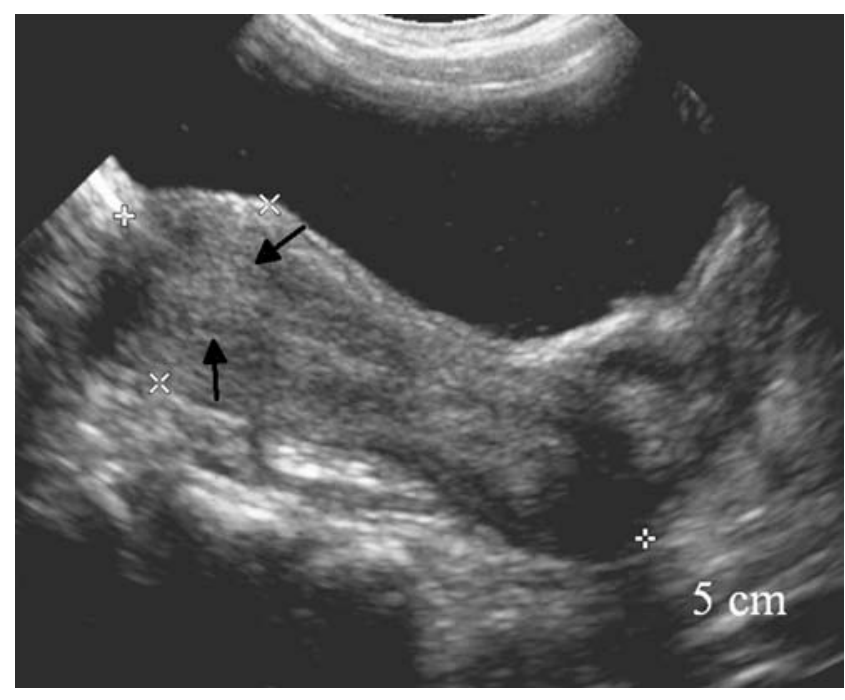

Fig. 2 US shows enlarged uterus with prominent endometrium

Leprechaunism is now classified under a group of endocrinopathies resulting in HAIR-AN syndrome (Hyperandrogenism, Insulin Resistance, Acanthosis Nigricans). Hyperinsulinemia stimulates hyperandrogenism, which manifests as precocious puberty in infancy [2]. While the clinical literature has briefly mentioned large ovaries in association with sexual precocity, the imaging appearance has not been previously shown.

\section{References}

1. Barbieri RL, Ryan KJ (1983) Hyperandrogenism, insulin resistance, and acanthosis nigricans syndrome: a common endocrinopathy with distinct pathophysiologic features. Am J Obstet Gynecol 147:90-101

2. Elsas LJ, Endo F, StrumlaufE et al (1985) Leprechaunism: an inherited defect in a high-affinity insulin receptor. Am J Hum Genet 37:73-88

Department of Radiology,

The Children's Hospital of Philadelphia,

324 South 34th St.,

Philadelphia, PA 19104, USA

e-mail: bellah@email.chop.edu 